\title{
Course Group Construction of Document Writing and Processing Ability of Applied Secretary Majors
}

\author{
Yinglu WANG \& Jiajuan LIU \\ Tianjin University of Science \& Technology, Tianjin, P.R. China
}

\begin{abstract}
The paper designs the construction of document writing and processing, therefore it puts forward the concept of document writing and processing course group, and formulates the course group related, in consideration of the working process of applied secretary majors' document writing and processing. Through the course group construction, the goal of improving the comprehensive professional ability of secretary majors will be achieved.
\end{abstract}

KEYWORD: Document Writing and Processing Course Group; Course Group Construction; Applied Secretary Majors

\section{INTRODUCTION}

Pan (2009) suggests that higher educational institutions be divided into three basic types. The first type is research universities where top innovative academic talents are cultivated. The second type is applied and professional universities or colleges which are multidisciplinary or single disciplinary to train senior practical and specialized personnel. The third type is higher vocational colleges where professional skilled personnel engaged in specific fields of production, management, and service is trained. In view of different kinds of specialized talents' training reality, Tianjin University of Science \& Technology is believed to share the common features with type one and type two. In view of the secretary majors' training reality, the main trainting objective is to cultivate senior applied secretary talents.

The abilities of document management, transaction management and conference management are the professional core that is required to be mastered by applied secretary majors. Especially, the document management ability is one of the most important. The document management ability mainly refers to the ability of secretary majors' document writing and processing. The paper is focused on the ability of secretary majors' document management.

\section{IDEAL OF DESIGNING THE SECRETARY MAJORS' DOCUMENT WRITING AND PROCESSING COURSE GROUP}

The professional core concepts and skills which should be mastered by applied college students cannot be acquired by learning one mere course. To achieve the desired training goal, a set of courses related is necessary to be learned as both preparation and subsequent consolidation. The course group construction will effectively promote the majors' professional potentialities and abilities, and enable the majors to become proficient in the occupation location and occupation selection.

Both the integrity of document writing and processing process and the comprehensiveness of the working process elements are focused on in the paper. The working process includes document writing, document delivery which includes document receiving and document sending, document filing and so on, which improves students' comprehensive ability of document management during the working process.

\section{DESIGN AND DISTRIBUTION OF DOCUMENT WRITING AND PROCESSING COURSE GROUP IN SECRETARY TALENT TRAINING PROGRAMME}

To train the secretary majors' ability of the document writing and processing, one course, Practical Document Writing with forty-eight periods 
for one semester, is difficult to achieve the goal of helping the students master the required knowledge and practice it. With the focal point cultivating the ability of document writing and processing, the part studies the courses that can enable the majors to acquire the professional core abilities in the talent training programme, and discusses how to carry out the plan of multi courses comprehensive training.

During the process of formulating and adjusting Secretary talent training programme, the core ability of document writing and processing of secretary majors should be fully considered. Some courses of the system, which are associated with the core abilities are required to be absorbed targetedly. Both the basic and the professional course group to train document writing and processing ability, include Modern Chinese, Secretary Theory \& Practice, Practical Document Writing, Document Processing \& File Management, Comprehensive Training of Secretary Majors, reflects the comprehensive secretarial quality and ability. The core ability includes document writing ability and document processing ability. The courses with the objective of training the majors' document writing ability are Modern Chinese and Practical Document Writing, and the courses with the objective of training their document processing ability are Secretary Theory \& Practice, and Document Processing \& File Management. The following respectively explains different roles that different courses play in the course group.

\subsection{Modern Chinese}

To acquire the ability of document writing, the secretary majors need to master the skills of substance refining, material integrating, structure selecting and language using. Language using especially needs the help of Modern Chinese, which mainly trains the students' ability to use the language reasonablely and effectively and is a basic and compulsory course of secretary majors in the first semester. The course mainly includes voice, text, vocabulary, grammar and rhetoric. The skills related closely to document writing are grammar and rhetoric. The moment a secretary gets the task of writing a document, he or she has got the inspiration from the leader or some files. Therefore, a secretary needs to be skilled at words in order to fulfill the leaders' requirements. Nowadays, grammar teaching of chinese language teaching is so ignored in primary and middle school that the students write articles following their hearts, but not following the grammatical and semantic rules. In the stage of the university, the requirements for language of the administrative documents in document writing is relatively strict and serious, and so students cannot write with language sense. Therefore, effectively designing and teaching the course is the basis of realizing the construction of document writing and processing course group.

\subsection{Secretary Theory \& Practice}

The course is a compulsory course of the secretary majors in the second semester, including secretarial jobs, secretary work agencies, communication and coordination work of the secretary, daily affairs of the secretary, the basis of document processing and file management, conference and reception, business activities and business travel, consultation, information research and so on. The basic part of document processing and file management in the course is the understructure of Documents Processing and File Management that is the required course of secretary majors in the sixth semester. It will lay a solid foundation for the students' document processing ability.

\subsection{Practical Document Writing}

This course is compulsory for secretary majors in the fourth semester, which plays a decisive role in training the students' document writing ability. The course mainly includes administrative document writing, clerical document writing and special document writing etc.. On the basis of Modern Chinese, the document writing ability is trained mainly through the course, which continues to cultivate the students' ability to use language, especially the ability to use language in document writing, together with which, other kinds of abilities including the main idea generalization and abstraction, material selection and integration and structure application etc., build secretary majors' knowledge structure and comprehensive ability of document writing.

Secretarial students have written literary style articles until they went to college, such as narration and prose. In the university, they write documents, many of which are very formal administrative documents. The students need take some time to adapt to, accept and reintegrate the knowledge structure. With the course learning, the ability of document writing of secretary majors will be more solid.

\subsection{Document Processing \& File Management}

This course is a compulsory course of secretary majors in the sixth semester. It plays an indispensable role in cultivating the ability of document processing. The "document processing" skill in Document writing and processing ability is mainly to implement and realize through the course. If the course is effective implementation of teaching on the basis of Secretarial Theory and Practice, secretarial talents will obtain the document 
processing capabilities including document compiling and making, document processing and document filing and so on.

\subsection{Comprehensive Practical Training of Secretarial Position}

This course is a comprehensive practical course of secretary majors in the seventh semester. It is the last link of the construction of document writing and processing curriculum group. The course is the comprehensive practice course to trains secretarial students' document writing and processing ability on the basis of many courses above.

The scope of the course group construction is not closed, it will gradually be adjusted with the development of professional direction, the actual situation of the students and the changes of the employment situation.

The following is the structure diagram of the document writing and processing ability.

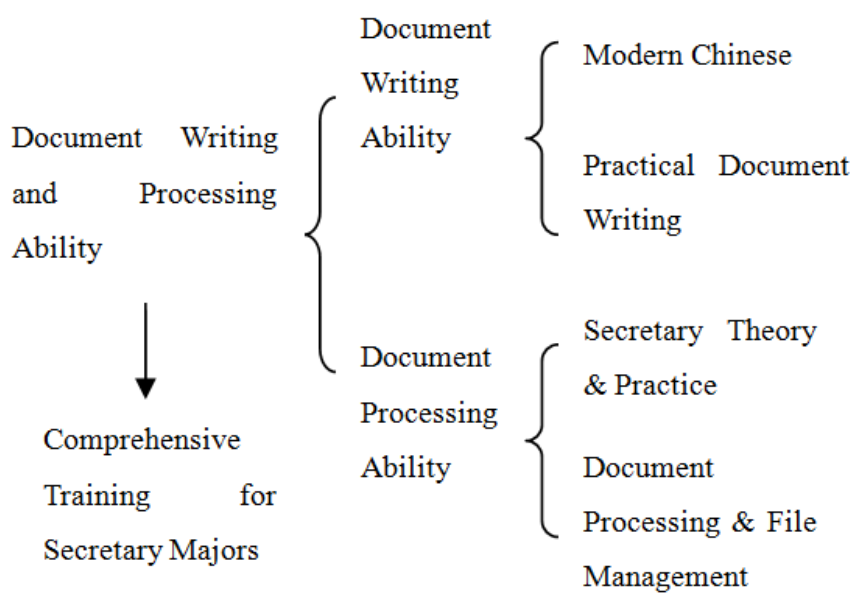

Figure1. The structure diagram of the document writing and processing ability

\section{PRACTICAL TEACHING AND LEARNING OF THE COURSE GROUP}

\subsection{Construction of the teaching team and different tasks of different teachers}

A teaching team composed of 3 to 5 teachers, should be built to teach different courses of the course group. Each teacher of the course group are required to master and teach 2 to 3 courses, and for each course there is a teaching echelon composed of 2 or 3 teachers.

The teachers in the course group are required to get the teaching concept of the course group, and instill in the students the significance and training objectives of the course group at the very beginning of teaching each course, make them understand it very well, and help them master the knowledge and skills of document writing and processing. Moreover, the teachers are required to learn about the scope and structure of the course group, be able to teach specific courses and evaluate comprehensively all aspects of the course group and the performance of the students.

\subsection{Training of the secretary majors}

With the teachers' help, during the period of the course group learning, the secretary majors are required to master the knowledge about document writing and processing, and know how to complete a task as a team player during the working process. Specifically, the working process of document writing includes explaining a writing task and then discussing, drafting, consulting, modifying, completing it and so on. The working process of document processing includes receipt, dispatch, document management, document collating and filing and so on. The students learn how to complete a task as a team player during the working processing, which is essential for them to understand the point of coordinating with others. For example, the procedure of document dispactch of document processing, reflects the importance of coordination. The whole process consists of drafting, examining and verifying, signing and issuing, reviewing, printing, registration and distribution etc.. Any one of the links is not to be completed by only one secretary, but by a union of the secretary, the leaders related and the collegues related.

\section{COMPREHENSIVE EVALUATION OF THE COURSE GROUP}

\subsection{Purpose of the evaluation}

Comprehensive evaluation of the course group does not aim to evaluate the scores, but focus on the comprehensive cultivation and improvement of students' document writing and processing ability. Evaluation is not the end, and not a destination. We take the construction of the course group as an opportunity to help the students really grasp the core skills of document writing and processing, and help students become skilled in the future job.

\subsection{Time of the evaluation}

The comprehensive evaluation is required to be finished before Comprehensive Training for Secretary Majors Course is started. That is the time point after Modern Chinese has been finished in the first semester, Secretarial Theory \& Practice has been finished in the second semester, Practical Document Writing has been finished in the forth semester, and Documents Processing \& File Management has been finished in the sixth semester. The evaluation of the finished courses is just the mid-term evaluation, which will guide the education 
of Comprehensive Training for Secretary Majors' Course.

\subsection{Range and content of the evaluation}

Take Practical Document Writing for example to show how to evaluate a course of the course group. Various types of documents will be taught in the course, in which there is a dozen of document types, requiring students to submit written assignment. At first, the students are required to write and modify their documents in class, their mistakes in the writing can be corrected and the scores can be given by the teacher at the first moment. Then, the results are recorded and the assignments are returned to the students for being corrected a second time. And then the modified documents are graded and recorded for the second time. Finally, the average of the two scores is taken as the final score.

All the scores for the assignments of different document types are required to be recorded and be made line charts in order that the students learn about their learning situation to make best use of the advantages and bypass the disadvantages.

Each course in the course group will be evaluated procedurally, not by a final examination. Since different courses need different kinds of evaluation, the evaluation will be studied further later.

\subsection{Improvement of the evaluation facing the future employment}

The overall comprehensive evaluation helps the students find their lengths and weaknesses, on the basis of which, the last course, Comprehensive Training for Secretary Majors for the seventh semester is required to be carried out, playing up strengths and avoiding weaknesses, to help the students see clearly their own conditions and promote the comprehensive ability of document writing and processing and therefore acquire the required practical ability before graduation.

\section{ACKNOWLEDGEMENT}

The paper is based on the Administrative Management Secretary Talent Training Programme of Tianjin University of Science Technology.

\section{REFERENCES}

[1] Maoyuan, Pan \& Qunying, Zhou. 2009. The Applied College Course Construction in the View of University Division. Chinese University Education, 3:4-7.

[2] Qingdian, Gao \& Yan, Wang \& Longbo, Qi. 2010. A Research on Practical Teaching System of the Course, Document Processing and File Management. Lantai World, 8:41-42.

[3] Yi, Wang \& Ying, Zhao. 2010. Documents Processing and File Management. Beijing: Peking University Press.

[4] Hua, Zhang. 2000. Course and Teaching Theory. Shanghai: Shanghai Education Press.

[5] International 21 century education committee. 1998. Learning: the treasure within. Beijing: UNESCO Publishing. 